\title{
A case report of decongestive therapy for treatment of lymphedema in a patient with breast cancer
}

\author{
Enkeleda Sinaj ${ }^{1}$ and Fatjona Kamberi ${ }^{2 *}$ \\ ${ }^{1}$ Faculty of Technical Medical Sciences, University of Medicine, Albania \\ ${ }^{2}$ Research Center of Public Health, Faculty of Public Health, University of Vlore "Ismail Qemali", Albania
}

\begin{abstract}
Lymphedema, one of the most common consequences of breast cancer treatment, associated with the accumulation of fluids with high protein content in the intercellular space except to dysfunction also creates an aesthetic problem for women. In addition, it increases the risk of skin infections and affects the quality of life. Here we report the case of a 37-year-old a female patient diagnosed with breast cancer who underwent left breast mastectomy and left lymph node axillary emptying. Six months after the treatment, the patient developed left-sided lymphedema. Based on the recommendation of the Oncologist decongestive therapy for lymphedema was initiated for 6 weeks with a frequency of 3 times a week. Decongestive therapy included manual lymphatic drainage according to Leduc, pressotherapy, and elastic-compression orthoses. The patient was also educated on exercise therapy with light physiological repetitive arm movements at home, on thoracic and diaphragmatic breathing as they have good decongestive effects. Decongestive Therapy although it does not affect the prevention of lymphedema, gives good results in the management and prevention of lymphatic stasis in breast cancer patients who have undergone surgery.
\end{abstract}

\section{Introduction}

Lymphedema is one of the most common consequences of breast cancer treatment. One in five women develops secondary lymphedema within the first 2 years after treatment [,]. It is associated with the accumulation of fluids with high protein content in the intercellular space. Clinically, the patient complains of severe sensation in the arm, paresthesia, and difficulty during daily life activities. In addition to dysfunction, lymphedema also creates an aesthetic problem for women, increases the risk of skin infections, and affects the quality of life. Breast cancer is associated with the emptying of axillary lymphatic stasis and radiotherapy. The development of secondary lymphedema is a major challenge for women due to the fact that it is a chronic problem. Decongestive therapy includes manual lymphatic drainage, pressotherapy, and exercise therapy and aims to stimulate lymph circulation and prevent lymphatic stasis [3-5].

\section{Case presentation}

A 37-year-old female patient was diagnosed with breast cancer in 2019. The patient underwent left breast mastectomy and left lymph node axillary emptying. 6 months after treatment, the patient developed left-sided lymphedema and was referred to Fisiomed Rehabilitation Center on the recommendation of the Oncologist for lymphedema decongestive therapy. The patient assessment consisted of measuring the crack circulation at several points. Measurements were done according to a low economic cost method of Latchford's Cassley-Smith widely used in the evaluation of lymphedema. For the measurement, the patient was placed with her arm in abduction $90^{\circ} .4$ reference points were selected for measuring circumferences, respectively: 0 points wrist at the level of the first palmar folding, point 2 folding the elbow, point 1 the middle of the distance between point 0 and 2, point 3 the middle of the distance between the acromial process and point 2 . Measurements were used to calculate limb volume according to the Kuhnke Vlimb formula, $\mathrm{V}_{\text {limb }}=\Sigma \pi\left(\mathrm{X}^{2}+\mathrm{Y}^{2}+\mathrm{XY}\right) \mathrm{h} / 3$.
$\mathrm{X}$ is the circumference of one of the reference points and $\mathrm{Y}$ is the $10 \mathrm{~cm}$ (h) circumference of X. Measurements were performed before the start of therapy and after 6 weeks at the end of it. The patient underwent decongestive therapy for 6 weeks with a frequency of 3 times a week. At the end, the patient placed the elastic-compression orthosis that held it for $12 \mathrm{~h}$. At the beginning of the treatment, there was a significant difference in volume between the left and right arm, $104 \mathrm{ml}$ or $16.5 \%$. At the end of treatment after 6 weeks the difference was $27 \mathrm{ml}$ or $4 \%$. The left-arm volume after treatment changed by $77 \mathrm{ml}$ or $10.5 \%$. The patient was also trained in exercise therapy with light physiological repetitive arm movements at home, for thoracic and diaphragmatic breathing.

\section{Discussion}

The results showed good effects of decongestive therapy in lymphedema management. Decongestive therapy included manual lymphatic drainage according to Leduc, pressotherapy, and elasticcompression orthoses [6,7]. According to Leduc, two are the basic techniques, drainage, and the opening of lymphatic pathways. Manual lymphatic drainage consists of light semi-circular movements of the hands-on the skin in order to empty the lymphatic congestion in the proximal parts of the limb and the lining of the lymph from the distal parts. Pressotherapy (intermittent pneumatic compression) is a mechanical decompression therapy that is performed by compression decompressing with air initially of the proximal parts then distal ones by means of an apparatus and lasts about 10 minutes. In conclusion, we can say that decongestive therapy, although it does not affect the

${ }^{*}$ Correspondence to: Fatjona Kamberi, Research Center of Public Health, Faculty of Public Health, University of Vlore "Ismail Qemali", Vlore, Albania, E-mail: fatjonakamberi@gmail.com / fatjona.kamberi@univlora.edu.al

Received: June 02, 2020; Accepted: June 20, 2020; Published: June 23, 2020 
prevention of lymphedema, gives good results in the management and prevention of the consequences of lymphatic stasis in breast cancer patients who have undergone surgery. Also, educating the patient about exercise therapy with light physiological repetitive movements of the arm at home, for thoracic and diaphragmatic breathing as they have good decongestive effects helps [8,9]. In addition, clinical trials suggest that decongestive therapy is effective not only in treating lymphedema but as well as in less pain and improves the quality of life of patients after breast cancer therapy [10]. Since there are not lymphedema management centers in Albania, this therapy can serve as a model both for the treatment of lymphedema and improving the quality of life of women with breast cancer.

\section{References}

1. Cheifetz O, Haley L (2010) Management of Secondary Lymphedema Related to Breast Cancer. Can Fam Physician 56: 1277-1284. [Crossref]

2. Dayes IS, Whelan TJ, Julian JA, Parpia S, Pritchard KI, et al. (2013) Randomized Tria of Decongestive Lymphatic Therapy for the Treatment of Lymphedema in Women with Breast Cancer. J Clin Oncol 31: 3758-3763. [Crossref]

3. Devoogdt N, Christiaens MR, Geraerts I, Truijen S, Smeets A, et al. (2011) Effect of Manual Lymph Drainage in Addition to Guidelines and Exercise Therapy on Arm Lymphoedema Related to Breast Cancer: Randomised Controlled Trial. BMJ 343: d5326. [Crossref]
4. Tastaban E, Soyder A, Aydin E, Sendur OF, Turan Y, et al. (2020) Role of Intermittent Pneumatic Compression in the Treatment of Breast Cancer-Related Lymphoedema: A Randomized Controlled Trial. Clin Rehabil 34: 220-228. [Crossref]

5. Castro-Sánchez AM, Moreno-Lorenzo C, Matarán-Peñarrocha GA, Aguilar-Ferrándiz ME, Almagro-Céspedes I, et al. (2011) [Preventing lymphoedema after breast cancer surgery by elastic restraint orthotic and manual lymphatic drainage: a randomized clinical trial]," Med Clin (Barc) 137: 204-207. [Crossref]

6. Ezzo J, Manheimer E, McNeely ML, Howell DM, Weiss R, et al. (2015) Manual Lymphatic Drainage for Lymphedema Following Breast Cancer Treatment. Cochrane Database Sys Rev 5: CD003475. [Crossref]

7. Bahtiyarca ZT, Can A, Ekșioğlu E, Cakcı A (2019) The Addition of Self-Lymphatic Drainage to Compression Therapy Instead of Manual Lymphatic Drainage in the First Phase of Complex Decongestive Therapy for Treatment of Breast Cancer-Related Lymphedema: A Randomized-Controlled, Prospective Study. Turk J Phys Med Rehabil 65: 309-317. [Crossref]

8. Baumann FT, Reike A, Reimer V, Schumann M, Hallek M, et al. (2018) Effects of Physical Exercise on Breast Cancer-Related Secondary Lymphedema: A Systematic Review. Breast Cancer Res Treat 170: 1-13. [Crossref]

9. Cho Y, Do J, Jung S, Kwon A, Jeon JY, et al. (2016) Effects of a Physical Therapy Program Combined with Manual Lymphatic Drainage on Shoulder Function, Quality of Life, Lymphedema Incidence, and Pain in Breast Cancer Patients with Axillary Web Syndrome Following Axillary Dissection. Support Care Cancer 24: 2047-2057. [Crossref]

10. Mondry TE, Riffenburgh RH, Johnstone PAS (2004) Prospective Trial of Complete Decongestive Therapy for Upper Extremity Lymphedema after Breast Cancer Therapy. Cancer J 10: 42-48. [Crossref]

Copyright: (C2020 Sinaj E. This is an open-access article distributed under the terms of the Creative Commons Attribution License, which permits unrestricted use, distribution, and reproduction in any medium, provided the original author and source are credited. 